\title{
Sobre a interação entre lajes $\epsilon$ núcleo Estrutural sujeito a empenamento $\in m$ edifícios altos de concreto armado
}

\author{
WAGNER QUEIROZ SILVA - D.Sc, PROFESSOR \\ Universidade Federal do Amazonas - DEC/FT/UFAM
}

\section{RESUMO}

EM PROJETOS DE EDIFíCIOS ALTOS É COMUM O USO DE NÚCLEOS RÍGIDOS PARA COMBATER ESFORÇOS HORIZONTAIS E REDUZIR A FLEXIBILIDADE DA EDIFICAÇÃO. EXISTEM DIFERENTES MANEIRAS DE SE MODELAR ESSE TIPO DE ESTRUTURA E MUITOS MODELOS USUAIS NÃO CONSIDERAM OS EFEITOS DA INTERAÇÃO ENTRE O NúClEO E A ESTRUTURA do PAVIMENTO. NESTE TRABALHO REALIZA-SE UM ESTUDO COM DIFERENTES MODELOS NUMÉRICOS PARA ANÁLISE DE EDIFÍCIOS DE CONCRETO ARMADO COM NÚCLEOS RÍGIDOS, BUSCANDO IDENTIFICAR A INFLUÊNCIA DA INTERAÇÃO ENTRE AS LAJES E AS PAREDES DO NÚCLEO NO FUNCIONAMENTO MECÂNICO DA EDIFICAÇÃO. APÓS UMA BREVE REVISÃO DE MODE-

LOS NUMÉRICOS EXISTENTES PARA MODELAGEM DE NÚCLEO RÍGIDO, AVALIA-SE UM EXEMPLO COM APLICAÇÃO DESTES MODELOS, COMPARANDO RESULTADOS DE DESLOCAMENTOS DA ESTRUTURA AO LONGO DE SUA ALTURA. BUSCA-SE AVALIAR OS EFEITOS DO EMPENAMENTO DAS PAREDES DO NÚCLEO SUJEITO À TORÇÃO NA ESTRUTURA DOS PAVIMENTOS. CONSTATA-SE QUE O EMPENAMENTO DO NÚCLEO PODE PRODUZIR DESLOCAMENTOS VERTICAIS NA LAJE FORA DE SEU PLANO, E QUE APENAS MODELOS QUE CONSIDERAM OS EFEITOS DA FLEXO-TORÇÃO SÃO CAPAZES DE DETECTAR TAL FENÔMENO. ESTA CONSIDERAÇÃO É DE GRANDE IMPORTÂNCIA EM CASO DE TORÇÃO NOS EDIFÍCIOS.

Palavras-chave: edifícios altos, núcleo estrutural, modelagem estrutural, empenamento.

\section{INTRODUÇÃO}

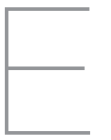

$m$ estruturas de edifícios altos de concreto armado é comum o uso de núcleos rígidos associados a pórticos para atribuir maior rigidez às ações horizontais, reduzindo assim os efeitos devidos a essas ações. Nesses casos, o núcleo rígido constitui parte da estrutura monolítica do edifício em conjunto com as lajes, vigas e pilares.

Nos modelos de análise convencionais, a estrutura é dividida de tal forma que as peças estruturais são analisadas em separado, a fim de facilitar o dimensionamento. Distinguem-se lajes e vigas como elementos que constituem o pavimento, repassando em seguida as reações destas ao subsistema vertical, formado por pórticos e paredes estruturais. Muitos admitem que a laje funcione como um diafragma infinitamente rígido no seu plano, compatibilizando os deslocamentos horizontais, o que simplifica o modelo. Essas aproximações, no entanto, não consideram as reais interações entre as peças que constituem a estrutura. No caso dos edifícios de concreto armado, a ligação monolítica entre peças faz com que haja uma transmissão de esforços que muitas vezes pode não estar sendo considerada da maneira mais adequada.
Com a evolução das tecnologias, algumas simplificações perderam sentido e até mesmo aplicação. As paredes dos núcleos rígidos e as lajes, atualmente, são executadas com espessuras menores do que no passado e para edifícios com alturas cada vez maiores, isto é, resultando em estruturas mais esbeltas. Os avanços tecnológicos e ferramentas computacionais permitem hoje análises mais elaboradas de forma a considerar mais adequadamente o comportamento mecânico das estruturas.

No presente trabalho é realizado um estudo numérico de edifícios de concreto armado com núcleo rígido 
buscando avaliar, para diferentes modelos, os efeitos da interação entre as lajes e as paredes do núcleo quando este sofre empenamento.

\section{MODELOS PARA EDIFÍCIOS COM NÚCLEO RÍGIDO}

\section{I Os primeiros modelos}

A metodologia simplificada conhecida como técnica do meio contínuo teve grande destaque no passado. Consiste basicamente em substituir elementos horizontais (lajes e vigas), que conectam os diversos painéis rígidos, por meios contínuos de rigidez equivalente, distribuídos ao longo da altura do edifício. Com isso, é possível equacionar esforços e deslocamentos da estrutura em função da variável altura, transformando a análise do edifício em um problema unidirecional. A grande vantagem é a redução do número de parâmetros, porém, o método é restrito a estruturas que apresentem características elásticas e geométricas constantes ao longo da altura. O uso de tal processo era impulsionado em função dos limitados recursos computacionais da época, estando atualmente em desuso.

Outros processos de análise de edifícios são a análise matricial e o método dos elementos finitos reticulados. Estes métodos passaram a ser mais utilizados com os avanços dos computadores, que permitem o processamento da estrutura dividida em vários elementos discretos. Neste sentido, um modelo mais simples é o modelo bidimensional no qual os painéis de contraventamento, incluindo o núcleo, são ligados através da laje, que atua como diafragma rígido. O modelo plano apresenta limitações, uma vez que não é possível analisar efeitos tridimensionais como a torção do edifício. Alguns projetistas de estruturas procuram evitar distribuições assimétricas de painéis e núcleos rígidos em planta, a fim de reduzir os efeitos de torção e justificar, assim, a análise com modelo plano.

Modelos discretos em pórticos tridimensionais proporcionam maior representatividade da estrutura global, já que se consideram a distribuição espacial entre os diversos painéis e, consequentemente, tem-se melhor representação da transmissão de esforços entre as peças (CORREA, 1991). O modelo de pórtico tridimensional é passível de aplicação, porém a análise do núcleo poderá ser comprometida se a hipótese de manutenção de seções planas for admitida, pois a mesma não se aplica a estes elementos quando sujeitos à torção. Neste caso, o comportamento mecânico deve levar em conta a teoria de flexo-torção.

Uma alternativa consiste em dividir o núcleo em pilares-paredes isolados, permitindo a aplicação do modelo de pórtico 3D e tornando o proces- so mais simples. Esse processo costuma ser utilizado em escritórios de cálculo estrutural devido a sua praticidade. Porém, esse tipo de simplificação também não deverá ser a mais representativa, pois não são consideradas as forças de cisalhamento que surgem na interface de encontro das paredes, fazendo com que estes elementos isolados não possuam a mesma rigidez que o núcleo, principalmente em relação à torção.

\subsection{Modelos por analogia de pórtico $\in$ treliça}

Um modelo alternativo para análise de paredes estruturais consiste em substituir as paredes planas por um conjunto de vigas horizontais rígidas com suas extremidades em balanço e engastadas em colunas verticais centrais, cujas propriedades geométricas são semelhantes a da parede que esta substitui. No caso de estruturas 3D, o núcleo é substituído por uma espécie de pórtico equivalente, conforme a Figura 1(b).

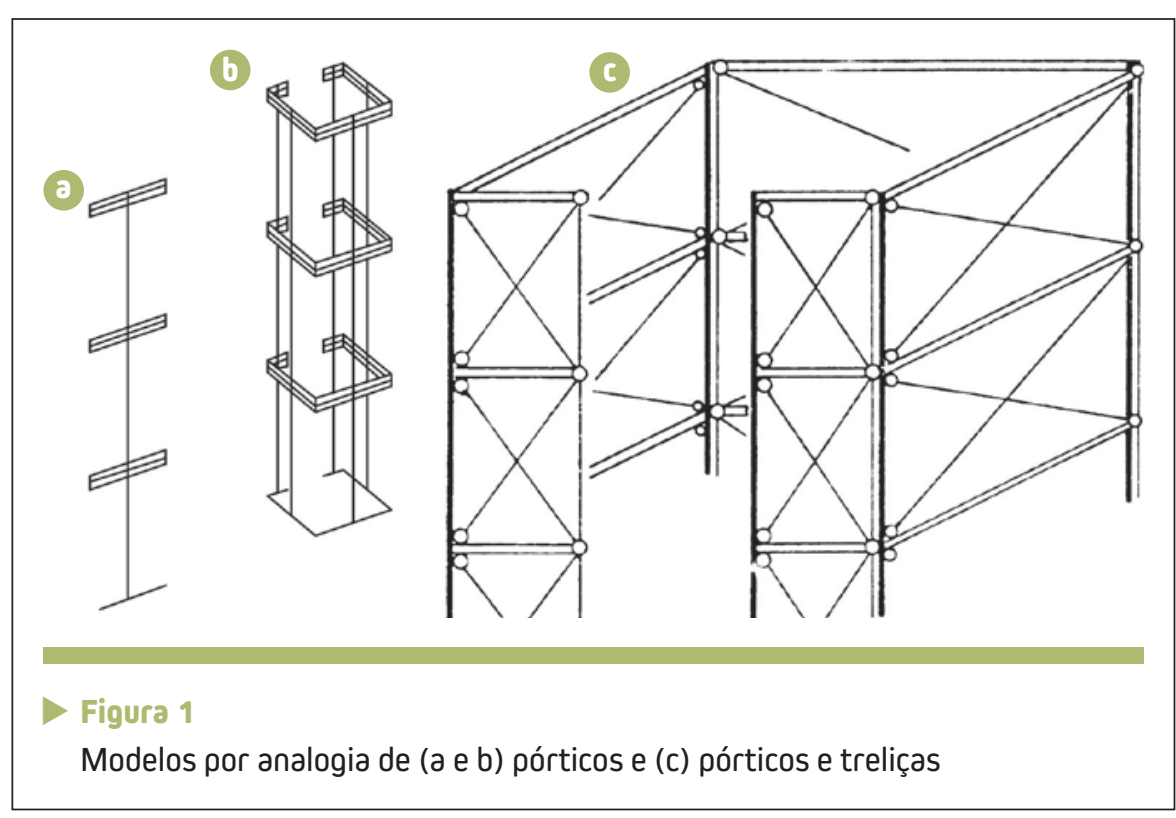


A proposta se baseia na ideia de que o núcleo resistente comporta-se como associação de estruturas de paredes delgadas e as vigas horizontais estão sempre dispostas aos níveis dos diafragmas rígidos. $\mathrm{O}$ modelo considera a rigidez à força normal, à flexão, à torção e à força cortante, através de trechos de pilares que substituem o sistema contínuo de paredes planas. Permite, portanto a aplicação de técnicas matriciais para análise dos núcleos fazendo uma analogia a um sistema de barras.

Outro modelo nessa linha considera elementos de barras diagonais contraventando uma treliça tridimensional equivalente ao núcleo rígido, a fim de considerar de maneira simplificada a rigidez axial das paredes, conforme a Figura 1(c).

\subsection{Modelos mais recentes}

O método dos elementos finitos permite uma variedade muito grande de aplicações, principalmente pela existência de diversos tipos de elementos finitos disponíveis na bibliografia. Uma possibilidade é a modelagem dos pilares-paredes com malhas de barras, adequando as propriedades de rigidez destas barras para simular o comportamento das paredes. É preciso, no entanto, avaliar com cautela os efeitos da flexo-torção (MEDEIROS, 2014). No caso dos núcleos estruturais, outra possibilidade é o uso de elementos de casca, o que permite a modelagem das paredes considerando suas continuidades e também as rigidezes à flexão e às forças axiais (PEREIRA, 2000).

Dentre as vantagens de se utilizar a modelagem em elementos de cas- ca, cita-se a maior representatividade do núcleo, uma vez que tendem a se aproximar do meio contínuo real. Não há necessidade de configurar as hipóteses cinemáticas relacionadas à flexo-torção, pois os graus de liberdade da casca são suficientes para captar esse tipo de fenômeno, além das instabilidades das paredes de pequena espessura.

A desvantagem é que ao utilizar elementos de casca, o modelo envolve um número maior de graus de liberdade na medida em que toda a superfície das paredes é discretizada. Quanto menor for o tamanho do elemento finito adotado, maior será a quantidade de elementos necessária para a malha discreta, o que aumenta o número de variáveis envolvidas.

Existem também outros tipos de elementos finitos especiais para núcleo, encontrados na bibliografia. Geralmente, a formulação é baseada na teoria de flexo-torção na tentativa de reduzir a quantidade de graus de liberdade, sem perda de representatividade do modelo (SILVA, 2014). Porém, observa-se que os softwares comerciais ainda não oferecem este tipo de elemento e, por este motivo, não será tratado no presente trabalho.

\subsection{Sobre o acoplamento do núcleo com a laje}

Alguns dos modelos de cálculo negligenciam a relação entre todos os componentes da estrutura de um edifício, a fim de facilitar o seu dimensionamento. Em estruturas usuais, esse tipo de simplificação pode ser aceitável e, às vezes, até conduzir a resultados satisfatórios. Porém, é importante atentar que, em alguns casos,

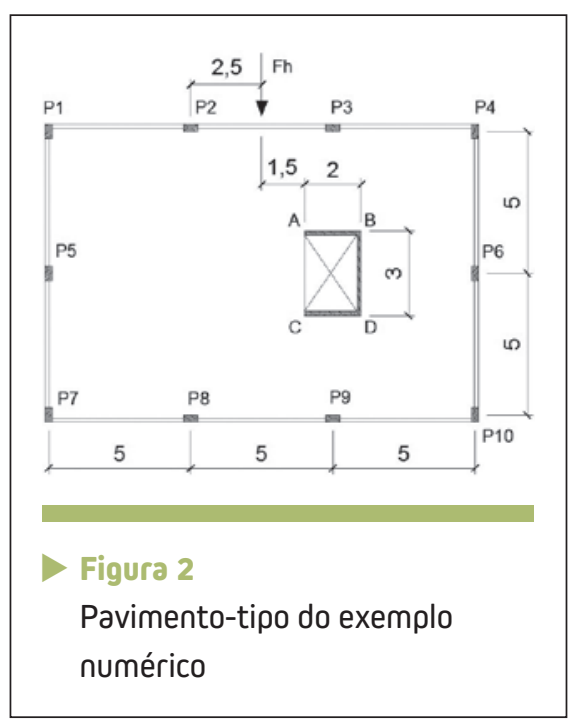

tais simplificações podem não ser as mais adequadas, principalmente em projetos de edifícios esbeltos onde o comportamento global é altamente dependente das interações entre os elementos estruturais.

Trabalhos como o de (SOUZA JR, 2001) e (SILVA, 2014) exemplificam a influência da modelagem de núcleos na análise de edifícios. Estes autores recomendam que não sejam utilizados modelos que não consideram a teoria da flexo-torção na análise de edifícios que possam apresentar rotações significativas, uma vez que esses modelos não conseguem representar adequadamente o empenamento dos núcleos.

Existem modelos onde a interação entre núcleos rígidos e lajes de edifícios são analisadas por elementos finitos de barra especial, com as considerações de seções generalizadas e as lajes geralmente simuladas com elementos de placa. Esses trabalhos permitem a verificação da influência das interações entre peças no comportamento global de edifícios, porém a maioria dos softwares comerciais ainda não dispõe desses recursos, 


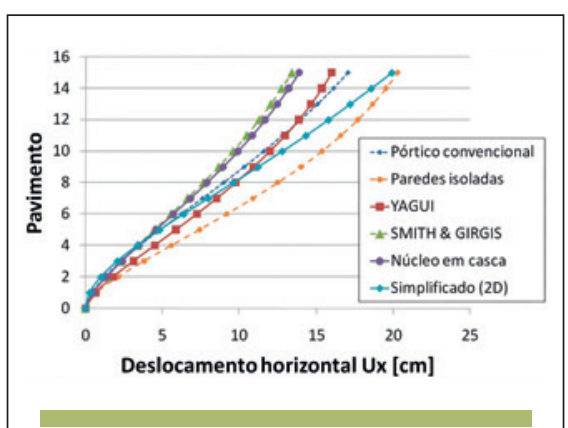

Figura 3

Resultados de deslocamentos horizontais

motivo pelo qual não serão abordados no presente trabalho.

A seguir apresenta-se o exemplo numérico avaliado por diferentes modelos para se verificar a influência da interação entre as lajes e as paredes do núcleo.

\section{EXEMPLO NUMÉRICO: EDIFÍCIO COM NÚCLEO SUJEITO À TORÇÃO}

O exemplo consiste de uma estrutura hipotética de edifício com 15 pavimentos, pé-direito de 4 metros e planta do pavimento tipo conforme a Figura 2. As vigas têm seção 20 $\mathrm{cm} \times 60 \mathrm{~cm}$, e os pilares de $25 \mathrm{~cm}$ x $50 \mathrm{~cm}$ estão localizados no perímetro da planta. As lajes e as paredes do núcleo possuem espessura de $15 \mathrm{~cm}$. O módulo de elasticidade é de 20 GPa e o coeficiente de Poisson 0,25. Consideram-se forças horizontais $\mathrm{Fh}=100 \mathrm{kN}$ aplicadas em todos os pavimentos. Com isso, pretende-se avaliar os efeitos globais de flexão e torção no edifício. Foi utilizado o software SAP 2000 e foram consideradas neste trabalho análises estáticas lineares e as fundações rígidas.

Foram considerados cinco modelos diferentes, variando a manei- ra como o núcleo é modelado. No primeiro modelo de pórtico convencional, o núcleo é simulado como elemento de barra simples 3D; o segundo modelo considera paredes isoladas, sendo o núcleo dividido em um conjunto de três paredes, sem considerar a interação entre as mesmas; o terceiro modelo adotado é o de pórtico denominado Yagui, com vigas horizontais rígidas e uma barra vertical central; o quarto modelo é baseado na proposta de analogia de treliça com diagonais de contraventamento de Smith \& Girgis (1984 apud SILVA, 2014) simulando as paredes; no último modelo o núcleo é discretizado em elementos finitos de casca. Para todos os casos, as lajes foram discretizadas em elementos de casca e os pilares e vigas com elementos de barra convencional. Observa-se que cada modelo trata a ligação entre laje e paredes do núcleo de maneira totalmente distinta. A intenção é analisar a influência de sua modelagem e também da vinculação deste elemento com o pavimento no comportamento global do edifício.

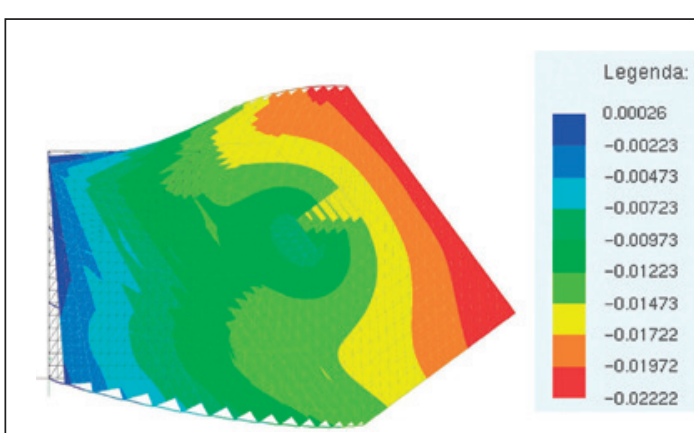

(a) Deslocamentos verticais nas lajes [m]

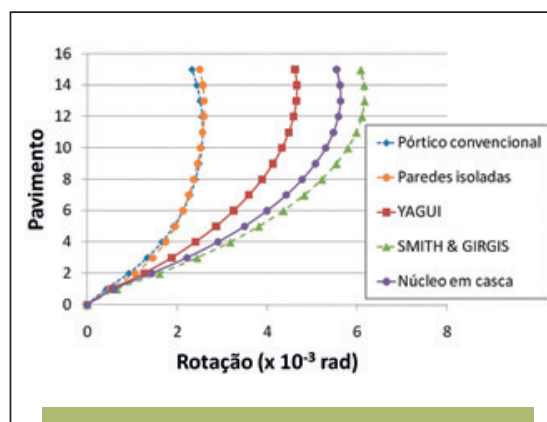

Figura 4

Resultados de rotações em relação a vertical

Os resultados de deslocamento horizontal e de rotação em torno do eixo vertical para o ponto $C$ de cada pavimento são apresentados nas Figuras 3 e 4. Observa-se que o modelo de pórtico convencional e o de paredes isoladas apresentaram maior flexibilidade à translação e menores rotações. Para fins comparativos, o deslocamento foi também analisado com modelo simplificado 2D. No caso plano, modelam-se o núcleo e os pórticos transversais, sendo estes vinculados com barras horizontais fictícias de rigidez infinita (diafragmas rígidos).

Essa flexibilidade se deve ao fato desses modelos não considerarem a rigidez do núcleo. O modelo
Figura 5

Aspecto amplificado da deformada do edifício 


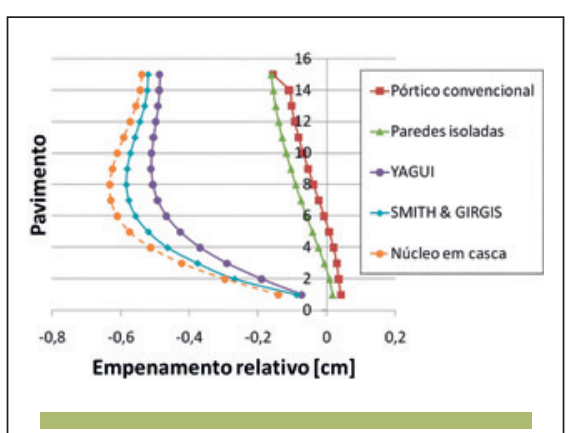

Figura 6

Empenamento relativo no núcleo

de analogia de pórtico-treliça foi o que mais se aproximou do modelo discretizado em cascas, o que demonstra sua eficiência.

A Figura 5 exibe configurações deformadas da estrutura vista em planta e lateralmente para o modelo com analogia de pórtico-treliça. Apresentam-se os deslocamentos (verticais e horizontais) amplificados para auxiliar na análise. Observa-se que o núcleo enrijeceu a estrutura, ocasionando um movimento de giro de corpo rígido nos pavimentos em torno de um eixo vertical. Caso a rigidez à flexo-torção do núcleo não seja adequadamente considerada, os resultados de deslocamentos poderão ser equivocados, comprometendo assim a análise em serviço da movimentação lateral do edifício. Erros no cálculo da rigidez podem também comprometer a correta distribuição de esforços.

Foi analisado também o empenamento relativo das paredes do núcleo (entre os pontos A e C) de cada pavimento. Os resultados apresentados na Figura 6 demonstram haver movimentação na direção vertical (empenamento). Somente os modelos que consideram a teoria de flexo-torção são capazes de detectar tal deslocamento. Os modelos simplificados apresentam apenas efeitos da simples translação dos pavimentos.

Os modelos usuais não consideram o fenômeno do empenamento. Para edificações esbeltas solicitadas a flexo-torção ou, quando os esforços atuantes no núcleo têm maior magnitude, esses efeitos podem alcançar níveis que interferem no comportamento global do edifício, comprometendo a análise dos deslocamentos devido às ações horizontais. A Figura 7 ilustra de maneira amplificada os efeitos do empe-

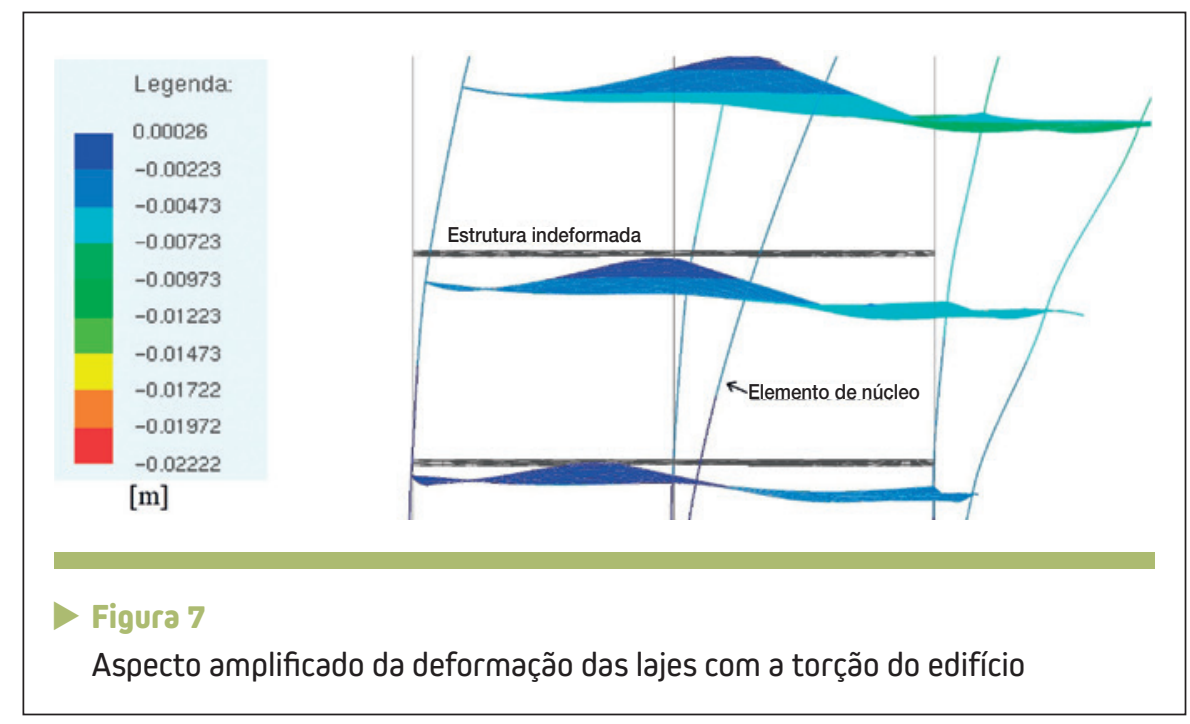

namento na estrutura do pavimento.

A influência da rigidez das lajes no comportamento do edifício também foi analisada considerando diferentes espessuras para as lajes. Os resultados de deslocamentos horizontais do núcleo são apresentados na Figura 8 , na qual se observa que, quanto mais espessa for a laje, mais rígida se torna a estrutura do edifício.

\section{CONCLUSÕES}

Dentre os modelos mecânicos de núcleo aqui considerados, alguns foram capazes de simular o comportamento de flexo-torção, sendo por esse motivo mais representativo. Os modelos simplificados, especialmente o de pórtico convencional e de paredes isoladas, não oferecem resultados suficientemente seguros. As limitações devido a não consideração dos efeitos da flexo-torção e das reais interações entre a laje e as paredes do núcleo são os motivos para tal imprecisão.

Modelos mais simplificados se mostram mais conservadores. De maneira geral, o exemplo demonstrou que a facilidade de aplicação dos modelos é inversamente proporcional a qualidade dos resultados obtidos.

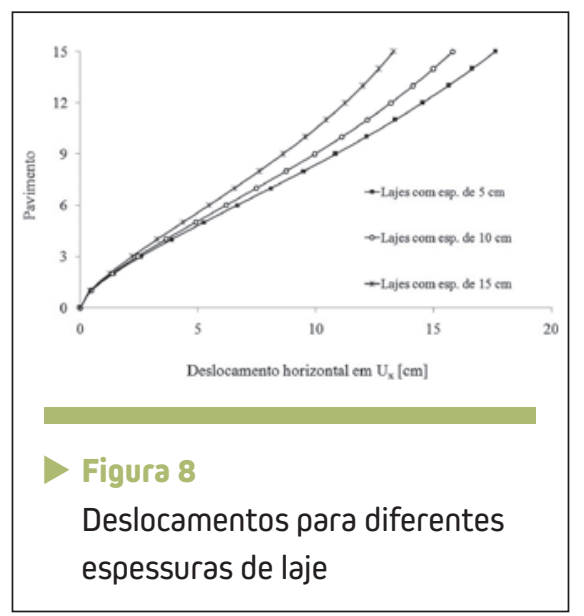


Dentre os modelos com analogia de barras, o modelo denominado por Smisth \& Girgis (1984 apud SILVA, 2014) se mostrou mais rígido do que o modelo de Yagui (1978 apud SILVA, 2014), além de valores mais próximos ao modelo de casca.

Em relação à interação entre a laje e as paredes do núcleo, fica clara a influência da rigidez no em- penamento da seção transversal do núcleo no comportamento global do edifício. Essa influência será maior para o caso de edifícios esbeltos. A região de vinculação das paredes e das lajes pode demandar maior consumo de aço para as armaduras por conta da concentração de tensões.

Acredita-se que alguns fatores como a fissuração do concreto e as altas taxas de armaduras nas regiões de ligação podem contribuir para uma redução dos efeitos da interação entre o núcleo e o pavimento, porém muitas vezes, sem o devido controle por parte do projetista. É preciso ter ciência de que o comportamento global do edifício depende das ligações entre as diversas peças estruturais.

\section{DREFERÊNCIAS BIBLIOGRÁFICAS}

[1] CORREA, M. R. S. Aperfeiçoamento de modelos usualmente empregados no projeto de sistemas estruturais de edifícios. Tese (Doutorado), Escola de Engenharia de São Carlos, EESC-USP. São Carlos/SP, 1991

[2] MEDEIROS, S.R.P. Modelos estruturais de núcleos de edifícios - barra vs. casca. TQS News, São Paulo, n. 39, p. 29-35, ago. 2014.

[3] PEREIRA, A.C. de 0. Estudo da influência da modelagem estrutural do núcleo nos painéis de contraventamento de edifícios altos. Dissertação (Mestrado), EESC-USP, São Carlos, 2000.

[4] SILVA, W. Q. Sobre análise não linear geométrica de edifícios considerando o empenamento dos núcleos estruturais e a interação solo-estrutura. Tese (Doutorado), Escola de Engenharia de São Carlos, EESC-USP. São Carlos/SP, 2014

[5] SOUZA JR, E. Análise da interação entre núcleos estruturais e lajes em edifícios altos. Tese (Doutorado), Escola de Engenharia de São Carlos, EESC-USP. São Carlos/SP, 2001.

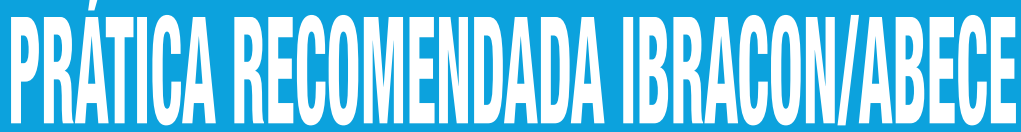

\section{Macrofibras poliméricas para concreto destinado a aplicaçoes estruturais:' definições, especificações e conformidade}

Elaborada pelo CT 303 - Comitê Técnico IBRACON/ABECE sobre Uso de Materiais não Convencionais para Estruturas de Concreto, Fibras e Concreto Reforçado com Fibras, a Prática Recomendada especifica os requisitos técnicos das macrofibras poliméricas para uso em concreto estrutural.

A Prática Recomendada abrange macrofibras para uso em todos os tipos de concreto, incluindo concreto projetado, para pavimentos, pré-moldados, moldados no local e concretos de reparo.

\section{A Q U I S I C Ã O}

www.ibracon.org.br (Loja Virtual)

\section{DADOS TÉCNICOS}

ISBN: 978-85-98576-29-9

Edição: $1^{\mathrm{a}}$ edição

Formato: eletrônico

Páginas: 37

Acabamento: digital

Ano da publicação: 2017

Coordenador: Eng. Marco Antonio Carnio
PRÁtICA RECOMENDADA IBRACON/ABECE MACROFIBRAS POLIMÉRICAS PARA CONCRETO DESTINADO A APLICAÇÕES ESTRUTURAIS

Patrocínio

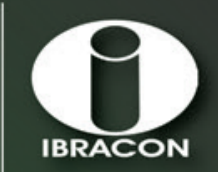

COMITẺ 303: Materiais não convencionais para Estruturas de Concreto, Fibras e Concreto GT4: Caracterização de moteriais nio

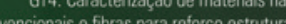
convencionais e fibras para reforço estrutura Coordenador: Eng. Marco Antonio Carmio Representante CTA: Sofia Maria Carrato Dinis 